\title{
Test Psicofísico Para Clasificar Turistas de Alta, Media y Baja Montaña: Una Propuesta Metodológica
}

\author{
Andrea Isabel Andrade Ayala, MsC \\ Manuel Antonio Abarca Zaquinaula, MsC \\ Diana Karina Vinueza Morales, MsC \\ Milton Alberto Sampedro Arrieta, MsC \\ Docentes Tiempo Completo de la Carrera de Turismo \\ Universidad Técnica de Cotopaxi (UTC), Ecuador
}

Doi:10.19044/esj.2020.v16n10p70 ＵRL:http://dx.doi.org/10.19044/esj.2020.v16n10p70

\begin{abstract}
Resumen
El presente trabajo consistió en diseñar un test psicofísico que evalué las condiciones médicas, psicológicas, técnicas y físicas de un turista, previo al ascenso a la montaña. Con base en la ponderación de los factores (médico, psicológico, técnico y físico) del test antes mencionado, se clasifica a los turistas en alta, media y baja montaña. Posterior a la clasificación de los turistas, se procede a la fase de aclimatación y /o capacitación. Para la elaboración del test psicofísico se entrevistó a médicos deportólogos y a guías especializados de la Unión Internacional de Asociaciones de Guías de Montaña (UIAGM), y de la Asociación Ecuatoriana de Guías de Montaña (ASEGUIM). El estudio tuvo como propósito, minimizar el riesgo de sufrir accidentes en la montaña, ocasionados por factores como: el clima, desprendimientos de roca o de índole humana provocados por la falta de conocimiento, mal estado de salud o falta de preparación técnica y/o física.
\end{abstract}

Palabras claves: Montañismo, Aclimatación, Test Psicofísico, Turista 


\title{
Physical, Medical, Psychological and Technical Profile of a High, Middle and Low Mountain Tourist: A Methodological Proposal
}

\author{
Andrea Isabel Andrade Ayala, MsC \\ Manuel Antonio Abarca Zaquinaula, $\mathrm{MsC}$ \\ Diana Karina Vinueza Morales, $M s C$ \\ Milton Alberto Sampedro Arrieta, MsC \\ Docentes Tiempo Completo de la Carrera de Turismo \\ Universidad Técnica de Cotopaxi (UTC), Ecuador
}

\begin{abstract}
The present work consisted of designing a psychophysical test that evaluated the medical, psychological, technical and physical conditions of a tourist, prior to the ascent to the mountain. Based on the weighting of the factors (medical, psychological, technical and physical) of the aforementioned test, tourists are classified as high, medium and low mountain. After the classification of tourists, the acclimatization and / or training phase proceeds. For the preparation of the psychophysical test, sports physicians and specialized guides from the International Union of Associations of Mountain Guides (UIAGM), and the Ecuadorian Association of Mountain Guides (ASEGUIM) were interviewed. The purpose of the study was to minimize the risk of accidents in the mountains, caused by factors such as: the climate, rockfalls or of a human nature caused by lack of knowledge, poor health or lack of technical preparation and / or physical.
\end{abstract}

Keywords: Mountaineering, Acclimatization, Psychophysical Test, Tourist

\section{Introduction}

El montañismo es un deporte que implica la ascensión de altas montañas, también denominado alpinismo y andinismo. El montañismo es entonces una práctica deportiva en la cual convienen técnicas, conocimiento y habilidades, todas ellas orientadas al fin último que es alcanzar el punto más alto de la montaña en cuestión. Dentro del alpinismo conviven doce especialidades: media montaña, alta montaña, senderismo, expediciones, escalada deportiva, escalada clásica (en roca o en hielo), esquí de travesía, barroquismo, media maratón de montaña, maratón de montaña y duatlón en 
montaña. En tanto, cada una de las especialidades mencionadas dispone de sus propias técnicas deportivas, de entrenamiento, en lo que respecta a materiales y en medicina deportiva, aunque todas coinciden en algo, exceptuando a la escalada deportiva, y es que el escenario de juego es la mismísima naturaleza, con sus características y particularidades ambientales, situación que por supuesto variará dependiendo de la época del año en la cual se practique el deporte (García, 2011).

El Montañismo a nivel mundial principalmente se práctica en el Himalaya, los Alpes y los Andes. El Himalaya se encuentra ubicada en el continente Asiático, es un sistema montañoso que comprende más de cien cimas de una altitud superior a los 7.000 metros y diez de 8.000 y constituye una franja de picos y de macizos que se extiende formando un arco de más de 2.500 kilómetros de longitud y entre 200 a 500 de anchura. Esta franja montañosa está delimitada, al sur, por las tierras bajas de la India, y al norte por la altiplanicie del Tibet (Pellini, 2014). Los Alpes es el sistema montañoso más largo de Europa, con más de 100 millones de visitantes cada año, el sistema completo de los Alpes tiene una longitud de más de 1,200 kilómetros y se ubica completamente en Europa, a partir de la costa mediterránea. Posee varios picos que superan los 3,500 metros de elevación, y más de 1,200 glaciares. La línea de nieve cubre alrededor de 2,450 metros, con numerosos picos cubiertos permanentemente de nieve o de glaciares; estos permanecen por encima de los 3,500 metros de elevación, el más grande glaciar de los Alpes es el Aletsch ubicado en Suiza (McColl, R., 2015). La Cordillera de los Andes es un sistema montañoso ubicado en América del Sur, es la cordillera más larga de las tierras emergidas, y la segunda más alta del mundo después del Himalaya, tiene una longitud de aproximadamente 7,000 kilómetros, una anchura aproximada de 200 a 700 kilómetros y una elevación máxima de 6,961-6,962 metros, atraviesa la región occidental de América del Sur, desde la costa del Caribe hasta el extremo sur del continente, a través de 7 países: Colombia, Venezuela, Ecuador, Bolivia, Perú, Chile y Argentina. La cordillera se constituye por varias montañas y volcanes, entre los que se encuentran el Aconcagua, el Nevado Ojos del Salado, el Huascarán, el Chimborazo, el Nevado del Ruiz, el Galeras y el Bonet (McColl, R., 2015). En los Andes sobresale la Cordillera Blanca situada a 408 kilómetros al noreste de Lima, en plena zona tropical, que se extiende de sur a norte, unos $180 \mathrm{Km}$. de largo y está cubierta por extensos glaciares, siendo la cadena montañosa más alta de los Andes Peruanos y de las zonas tropicales en todo el mundo, cuenta con más de 35 picos nevados que superan los 6,000 metros de altura, allí se ubican los picos más altos del Perú y está coronado por el Nevado Huascarán, cuyo pico sur alcanza los 6,768 metros sobre el nivel del mar, considerado como el nevado más alto del Perú, y segundo de Sudamérica 
después del Aconcagua (nevado tropical más alto del mundo ubicado en Argentina con una altitud de 6,962 metros), (Nadal, 2016).

Ecuador es uno de los países privilegiados por ser parte del sistema montañoso de los Andes, se pueden encontrar alrededor de 50 montañas, que van a lo largo de la región sierra, conformada por la cordillera oriental y occidental de los Andes, denominada turísticamente como "Ruta de los Volcanes", entre las provincias de Pichincha, Carchi, Tungurahua, Chimborazo, Cañar, Azuay, Loja, Imbabura, Bolívar y Cotopaxi. Se caracteriza por sus elevaciones montañosas de gran altitud, siendo la montaña más básica para la práctica del montañismo el Putzalahua, ubicado en la provincia de Cotopaxi y la montaña más técnica los picos del nevado El Altar, ubicado en la provincia de Chimborazo (Turismo, 2015). El montañismo en el Ecuador es calificado como Andinismo, por el lugar geográfico en el que se encuentra ubicado y tiene una historia larga, y ha pasado por varias fases de desarrollo, con una sensibilidad distinta en cada una, desde el interés científico hasta el profesionalismo deportivo (ANBCR, 2010).

El portal internacional Switchback Travel ubica al Ecuador en quinto lugar como destino de turismo de aventura a nivel mundial. Por su ubicación geográfica, la presencia de la cordillera de los Andes, las corrientes marinas que vienen del norte y del sur, hacen de este país un destino incomparable para actividades de aventura y de turismo especializado de toda índole. En el 2015 cerca de 914.477 personas realizaron montañismo, según datos tomados dentro del Parque Nacional Cotopaxi, Reserva Ecológica Los Ilinizas y Reserva de reproducción faunística Chimborazo (Turismo, 2015). El montañismo en el Ecuador es uno de los deportes de mayor atracción para quienes disfrutan de la adrenalina y los paisajes, la mayor afluencia de turistas se da generalmente en el mes de Julio y agosto, denominado por el Ministerio de Turismo "tiempo de montañas", en estos meses son temporada alta para los refugios de montaña, transportistas y guías (Aves y Conservación, 2011). En un estudio realizado en Argentina menciona que la enfermedad más terrible y mortal en alta montaña es el edema pulmonar o cerebral, provocado por la escasez de oxígeno que ingresa a nuestro organismo. Bajo este criterio, un turista puede morir por no tener la capacidad física, psicológica, técnica, o no ser acompañado por un profesional capacitado que identifique las señales de un edema pulmonar o los peligros propios de la montaña (Devallenova, 2016). El poder determinar mediante la aplicación de un test, el perfil físico, psicológico y técnico de un turista de alta, media y baja montaña antes del ascenso, es indispensable para conocer la adaptabilidad de su cuerpo y mente ante los posibles impactos de la montaña, y evitar la pérdida de más vidas humanas en esta actividad. 


\section{Metodología}

El presente estudio es de enfoque cualitativo, siendo una investigación de alcance exploratoria que empleó el método Delphi con la técnica de la entrevista y revisión de información bibliográfica, para conocer la experiencia de algunos expertos en actividades físicas y montañismo. Se entrevistó a 2 médicos deportologos que laboran en el centro médico deportólogo "Asdrúbal de la Torre" de la ciudad de la ciudad de Quito y a 4 guías especializados en alta montaña: 2 guías pertenecientes a la Unión Internacional de Asociación de Guías de Alta Montaña, y 2 guías pertenecientes a la Asociación Ecuatoriana de Guías de Montaña. Con base en la opinión de los expertos antes mencionados se elaboró un test psicofísico de cuatro componentes o factores; médico, psicológico, técnico y físico. Con la ponderación de los resultados de los componentes antes mencionados se evalúa el estado físico, psicológico y de adaptabilidad de los turistas, previo al proceso de aclimatación y ascenso a las montañas.

\section{Población y muestra}

La investigación se llevó a cabo en Ecuador especialmente en las provincias de Pichincha y Cotopaxi, por docentes - investigadores de la carrera de Turismo de la Universidad Técnica de Cotopaxi, en cumplimiento al objetivo número 2 del proyecto experimental titulado "Estudio de las características físicas y psicológicas para determinar perfiles de excursionistas para alta, media y baja montaña”. Según el protocolo del método Delphi, en primera instancia se definió el cuestionario para entrevistar a los expertos con base en los objetivos y problemática de la investigación, se definió las preguntas con precisión, dándole validez de respuesta y de conocimiento al cuestionario. En segunda instancia se realizó un muestreo no probabilístico a conveniencia de los investigadores, por razones de ubicación geográfica, facilidad de contacto y experiencia, se seleccionó a los expertos de bases datos de centros deportólogos de la ciudad de Quito y asociaciones de guías especializados en alta montaña de Sudamérica y Ecuador, perfiles con más de 4 años de experiencia en actividades físicas y montañismo. En tercera instancia se procedió a realizar las entrevistas de manera aislada en diferentes tiempos y espacios, con la finalidad de obtener información real de cada uno de los expertos. La selección de expertos se realizó analizando las bases de datos de las siguientes organizaciones:

Centro Médico Deportólogo “Asdrúbal de la Torre”. Es un centro médico especializado en la salud del deportista, ubicado en la ciudad de QuitoEcuador, se encarga de dar a conocer los estados físicos y médicos necesarios para que una persona pueda realizar cualquier tipo de actividad con entrenamiento conciencia de su salud. La medicina del deporte y de la actividad física, es una especialidad multidisciplinaria que comprende 
aspectos médicos, técnicos, psicológicos y pedagógicos. Investiga y define las cargas de esfuerzo a las que puede someterse al individuo durante sus fases de entrenamiento y preparación, con el objeto de producir incremento biológico en la capacidad de esfuerzo, prevenir lesiones, trastornos y enfermedades, así como tratarlas y rehabilitarlas en cada caso (Homs, 2012).

Unión Internacional de Asociación de Guías de Alta Montaña (UIAGM). Se fundó en el año 1965, en aquel entonces fue conformada por cuatro países: Austria, Francia, Italia y Suiza. En la actualidad, la organización la conforman más de 20 países de casi todos los continentes representando a cerca de 6.000 guías certificados. En Sudamérica existen actualmente tres escuelas, la de Perú, Bolivia y Argentina, las que han formado a guías del resto de los países de Sudamérica, por lo que hoy también existen guías certificados de Colombia, Ecuador, Chile y Venezuela. Todos los guías UIAGM reciben un entrenamiento y una preparación durante un mínimo de tres años bajo los mismos estándares, tanto de seguridad como de capacidades físicas y técnicas en el ambiente de montaña, cubriendo todos los aspectos del mundo del montañismo. Para convertirse en un Guía de Alta Montaña profesional, cada aspirante debe cumplir un mínimo de requerimientos físicos, como el desenvolverse de manera fluida en los distintos terrenos de la montaña, necesitando un nivel mínimo en cada especialidad. Además, debe tener conocimientos generales de manejo de riesgos, medio ambiente (flora, fauna, geología, cultura), orientación, meteorología, avalanchas, rescate y primeros auxilios. Todos estos conocimientos son adquiridos en cursos separados a los cursos formativos de la UIAGM (Rojas, E., 2016).

Tabla. 1 Conocimientos de un Guía UIAGM

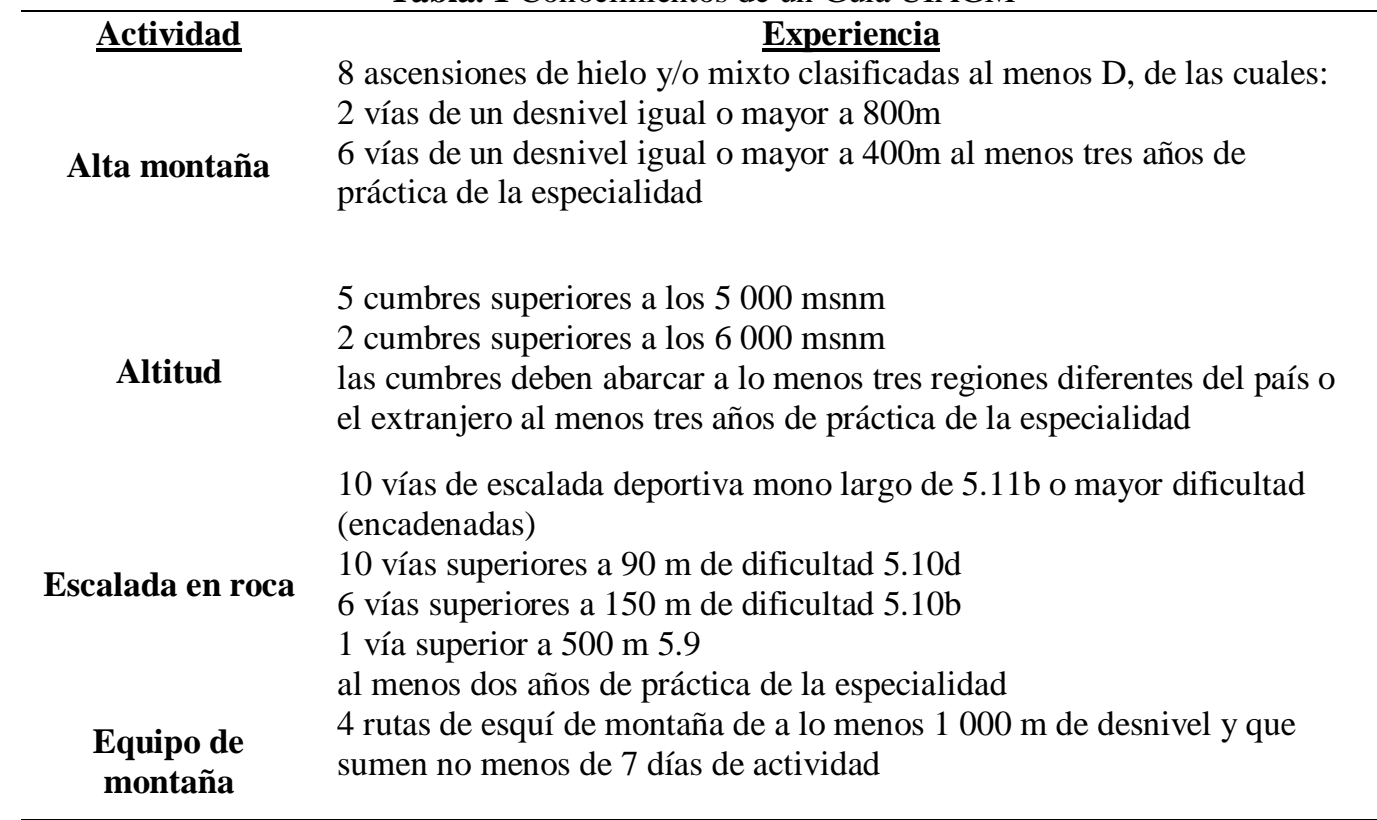


1 cumbre en esquí de más de $5000 \mathrm{msnm}$ al menos dos años de práctica de la especialidad.

Fuente: Adaptado de UIAGM (Rojas, E., 2016)

Asociación Ecuatoriana de Guías de Montaña (ASEGUIM). Inició como un conjunto de clubes de montañismo en el país en los años noventa, cuando el montañismo y la escalada tuvieron auge. Se encarga principalmente de dos funciones primarias; la primera, formar a guías certificados de montaña y escalada con fines turísticos, y la segunda realizar evacuación y rescate en el territorio ecuatoriano. La ASEGUIM dicta cursos dos veces al año, divididos en tres módulos como son: módulo de roca, módulo de hielo y nieve, y modulo alpino. En el examen se evalúan los tres módulos (ASEGUIM, 2015).

Tabla. 2 Conocimientos de un guía de ASEGUIM

\begin{tabular}{|c|c|}
\hline Actividad & Experiencia \\
\hline $\begin{array}{lll}\begin{array}{l}\text { Orientación } \\
\text { combinada }\end{array} & - & \text { estamina } \\
\end{array}$ & $\begin{array}{l}\text { Recorrido de aproximadamente } 40 \text { min sobre } 4000 \\
\text { msnm. }\end{array}$ \\
\hline Escalada deportiva en roca & De nivel mínimo 7a, puede llegar hasta 7b \\
\hline $\begin{array}{l}\text { Escalada en roca con bota de } \\
\text { montaña }\end{array}$ & De nivel $6 a+/ 6 b$ \\
\hline Todo terreno & $\begin{array}{l}\text { Circuito que incluye pasos de } 5 \mathrm{~b} / 5 \mathrm{c} \text {. el } 70 \% \text { debe ser } \\
\text { de } 3^{\text {er }} \text { grado y el resto }(30 \%) \text { de } 4^{\text {to }} \text { grado, se lo ejecuta } \\
\text { con mochila de } 10 \mathrm{~kg} \text {. (obligatoria bota que calce } \\
\text { crampón) }\end{array}$ \\
\hline Uso de equipo/estación & $\begin{array}{l}\text { Los participantes llevaran su propio rack, deben estar } \\
\text { encordados al extremo de una cuerda y deben montar } \\
\text { una estación en tradicional y auto asegurarse. }\end{array}$ \\
\hline Expresión libre & $\begin{array}{l}3 \text { min para demostrar todas las técnicas de piolet y } \\
\text { crampones que se sepa. Deben aplicar en terreno e } \\
\text { inclinación. }\end{array}$ \\
\hline Expresión impuesta & $\begin{array}{l}\text { Circuito de alrededor } 6 \text { minutos de pendientes } \\
\text { pronunciadas en hielo que se debe resolver con } \\
\text { técnicas clásicas. }\end{array}$ \\
\hline Escalada en hielo & Individual y con clientes. \\
\hline
\end{tabular}

Fuente: Adaptado de (ASEGUIM, 2019)

\section{Técnicas e instrumentos}

La entrevista desde el punto de vista del método, es una forma específica de interacción social que tiene por objeto recolectar datos para una indagación. El investigador formula preguntas a las personas capaces de aportarle datos de interés, estableciendo un diálogo peculiar, asimétrico, donde una de las partes busca recoger informaciones y la otra es la fuente de esas informaciones (BAENA, G., 2014). Se entrevistó a 2 médicos deportologos y 4 guías de alta montaña; 2 guías de la UIAGM y 2 guías de la ASEGUIM. El cuestionario se definió de la siguiente manera: 
Tabla 3. Cuestionarios para aplicar a los expertos

\section{Cuestionario para Médico Deportologo}

¿A qué personas reconocidas a formado dentro de este centro deportólogo?

¿Cómo fue el proceso de entrenamiento de aquellas personas?

¿Cómo considera que una persona debe empezar en el montañismo?

¿Qué ejercicios recomienda realizar a un turista que va a visitar la ruta de los volcanes de Ecuador?

¿Para un buen entrenamiento físico que ejercicios recomienda realizar a los turistas que vayan a visitar Ecuador?

¿De los ejercicios anteriormente nombrados cuales considera Ud. que deberían realizarse para un mejor rendimiento físico?

¿Considera Ud. que el realizar un adecuado entrenamiento físico baste para ascender una montaña?

\section{Cuestionario para Guía de Alta Montaña}

¿Qué actividad e indicaciones realiza a sus turistas antes de ascender una montaña?

¿Cómo evalúa el clima y terreno antes de una ascensión?

¿Cuál es el equipo que debe manejar un guía y un turista?

¿Qué conocimiento debe tener un guía sobre la montaña que va a ascender y su clasificación, ya sea alta, media o baja? ¿Cómo considera que una persona debe empezar en el montañismo?

¿Qué ejercicios recomienda realizar a una persona que se va a involucrar en el montañismo?

¿Considera Ud. que el realizar un adecuado entrenamiento físico baste para ascender una montaña?

Test físico. Consiste en valorar y medir el rendimiento que podemos hacer acerca de nuestras cualidades o capacidades físicas, deben hacerse después de un calentamiento físico adecuado y cumplir con protocolos de cada test para que sea confiable el resultado obtenido y se pueda realizar la interpretación que se desea (Sole, 2002). Con base en la información proporcionada por los expertos en las entrevistas, se elaboró un test psicofísico que evalúa cuatro componentes; médico, psicológico, técnico y físico, cada componente contiene sus respectivas preguntas de evaluación. La ponderación de los componentes clasifica a los turistas en alta, media y baja montaña.

\section{Resultados}

\section{Entrevista a Médicos Deportologos}

Experiencia como médico: alrededor de 4 años en el centro deportólogo "Asdrúbal de la Torre". Las entrevistas se realizaron en diferentes tiempos y espacios de manera aislada con la finalidad de obtener información real y no sesgada, y estas fueron sus respuestas:

¿A qué personas reconocidas a formado dentro de este centro deportólogo? Aquí en el centro Asdrúbal de la Torre, nosotros hemos tenido la oportunidad de ver el crecimiento deportivo de varios atletas, sobretodo de concentración deportiva de pichincha que realizan justamente actividades del montañismo y escalada principalmente y poderles dar el seguimiento en lo que ha sido su carrera deportiva. Personas reconocidas tenemos a Carla Pérez, Iván Vallejo, Juliana García. 
¿Cómo fue el proceso de entrenamiento de aquellas personas? El proceso ha consistido en darles seguimiento al menos una vez al año, a los chicos que forman parte de concentraciones deportivas, entonces lo que hacemos es la evaluación integral con el fin de que podamos primeramente determinar que no tengan ningún factor de riesgo y ningún problema para el inicio de su práctica deportiva, o en el caso de algunos chicos ya ese seguimiento con el cual ya vamos obteniendo los resultados a nivel competitivo en el caso de la escalada y en el caso del montañismo sobre todo conocer que objetivos tengan en el año de cumbres que quieran realizar y en base a eso proceder a una planificación.

¿Cómo considera que una persona debe empezar en el montañismo? El proceso en si de una persona que está interesada en el montañismo debe iniciar conociendo su estado general (físico-médico, mental y técnico), no necesariamente debe realizarse exclusivamente un seguimiento por un deportologo, porque la verdad es difícil acudir a algunos sitios sin contar con un buen acervo de médicos con esta formación, pero si se diera la oportunidad de contar con ellos sería ideal poder llevar un seguimiento en campo, además de conocer el factor riesgo en la montaña en cuanto males de altura que ya se han presentado en varios casos pero que en nuestro país no existe un estudio de campo que nos ayude a ver que otros riesgos se pueden presentar. Por lo general las personas que inician en lo que es el montañismo usualmente empiezan por caminar un tiempo estimado, hasta manejar mejor su tiempo de resistencia acompañado de hidratación y aclimataciones.

¿Qué ejercicios recomienda realizar a una persona que se va a involucrar en el montañismo? En el montañismo los ejercicios deben ser combinados, como el atletismo, natación y ciclismo que son actividades que van ayudando y permitiendo desarrollar diferentes cualidades tanto de resistencia física como de desarrollo pulmonar o resistencia cardiovascular con el fin de poder irse preparando para vencer retos de cumbres de alto nivel. Además se necesita una preparación técnica adecuada en lo que respecta a la actividad del montañismo, también es necesario estar preparado psicológicamente para afrontar de mejor manera los duros retos que enmarca este deporte, que paso a paso conforme va el ascenso se va convirtiendo en un deporte muy complejo y extremo, y por lo general los montañistas por querer hacer cumbre no miden adecuadamente las amenazas de los factores abióticos de la montaña y se produce la pérdida de vidas humanas. Podemos también argumentar que los ejercicios que nosotros en calidad de médicos deportologos empleamos para medir el estado físico y mental de una persona son los; test de Cooper, test de Wells, test de Burpees, test de Ruffier entro otros. 
¿Para un buen entrenamiento físico, que ejercicios recomienda realizar a los turistas que vayan a visitar la ruta de los volcanes de Ecuador? Cuando un turista está interesado en practicar el montañismo en nuestro país la recomendación ideal es adaptarse a la altura a través de un proceso de aclimatación e ir paulatinamente haciendo cumbres en diferentes alturas para que les permita ascender sin ninguna complicación. Afortunadamente Ecuador cuenta con guías especializados en alta montaña, que les pueden ayudar a la ascensión de montañas siendo ellos un elemento de ayuda también en cuanto a las aclimataciones.

¿De los ejercicios anteriormente nombrados cuales considera $U d$. que deberían realizarse para un mejor rendimiento físico? No existe un tipo de ejercicio especifico al cual le debamos poner mucho más énfasis, se recomienda combinar diferentes tipos de actividades deportivas y la aplicación de los test (Cooper,Wells,Burpees,Ruffier) antes mencionados previo al proceso de aclimatación y ascenso a las montañas, esto les permitirá conocer sus características y limitaciones físicas, y sobretodo preparar la parte muscular, pulmonar y cardiovascular para tener un ascenso exitoso.

¿Considera $U d$. que el realizar un adecuado entrenamiento físico baste para ascender una montaña? No solo es suficiente una buena preparación física en el montañismo, tenemos también que considerar la parte psicológica, técnica e incluso social, porque como en todos los deportes, no solo es la resistencia física y cardiovascular para alcanzar objetivos y metas, en el caso de montañismo no es diferente, por lo tanto, es fundamental una preparación integral de la persona en los aspectos; médico, físico, psicológico y técnico.

\section{Entrevista a guías de alta montaña}

Se presenta los resúmenes de las respuestas obtenidas de 4 guías especializados en alta montaña; 2 guías de la Unión Internacional de Asociación de Guías de Alta Montaña (UIAGM) y 2 guías de la Asociación Ecuatoriana de Guías de Montaña (ASEGUIM), de igual manera, las entrevistas fueron realizadas en tiempos y espacios diferentes de manera aislada para obtener información real.

¿Qué actividad e indicaciones realiza a sus turistas antes de ascender a una montaña? Antes de ir a una montaña se les da las instrucciones, que tipo de equipo y vestimenta va a necesitar, el tiempo estimado de la ruta, que alimentación debe llevar, indicaciones de cómo va a ser la ascensión y el posible cambio de clima que se dé en la montaña.

¿Cómo evalúa el clima y terreno antes de una ascensión? Para la evaluación del clima los guías tomamos la opción de verificar el pronóstico en una página web, un altímetro o un barómetro. En cuanto al terreno se observa los peligros objetivos que puedan hacer como: roca suelta, mojada, 
avalanchas, placas, grietas entre otras. Ahí es donde se verifica si contamos con el equipo adecuado, y si estamos en condiciones físicas y mentales para el ascenso o si no hay que cambiar la ruta o por ultimo abortar la misión.

¿Qué equipo que debe manejar un guía y un turista para la práctica del montañismo? Media montaña: zapatos de trekk, Pantalón de trekk, Pantalón impermeable, Camisa de polipropileno, Jersey fino y grueso, Chaqueta impermeable, Arnés (opcional), Guantes, Casco (opcional), agua y comida, Botiquín básico, Linterna (opcional). Alta montaña: botas de alta montaña, 2 pares de calcetines, Pantalones fino, polar, nylon o goretex. Camisa, jersey fino, grueso, chaqueta de pluma, gorro de lana, guantes finos y gruesos, Gafas UV, casco y linterna frontal, crampones y piolet, mosquetón de seguro, botella para agua o termo, arnés, sleeping bag, polainas, mochila 45 lt, botiquín, ph, cordinos, tornillos, bastones. Gps, protector uv. (Opcional), cuerda y estacas.

¿Qué conocimiento debe tener un guía en cuanto a la montaña y su clasificación ya sea alta, media o baja? Orientación en cualquier montaña, supervivencia, manejo de estaciones puede ser en roca o nieve, auto-rescate y rescate, manejo de equipos, conocimiento de rutas, primeros auxilios en zonas agrestes. En cuanto a la clasificación y características de las montañas en América del Sur se describen a continuación:

Tabla 4. Clasificación de una montaña según la altitude

\begin{tabular}{ccl}
\hline \multicolumn{1}{c}{ Nivel } & $\underline{\text { Altitud }}$ & \multicolumn{1}{c}{ Características } \\
\hline Baja Montaña & $(0-3.500 \mathrm{~m})$. & $\begin{array}{l}\text { Abunda la vegetación, excepto en zonas áridas } \\
\text { Fácil aproximación, carreteras, caminos, } \\
\text { refugios y núcleos habitados. } \\
\text { Múltiples actividades: excursionismo, } \\
\text { senderismo, orientación, acampada. }\end{array}$ \\
& & $\begin{array}{l}\text { Abundante vegetación en valles y barrancos } \\
\text { Escasez de vegetación arbórea. } \\
\text { Media Montaña }\end{array}$ \\
& $(3.600-4.800$ & $\begin{array}{l}\text { Menor presencia de animales } \\
\text { Actividades: excursionismo, acampada, } \\
\text { montañismo, escalada en roca, etc. }\end{array}$ \\
& & $\begin{array}{l}\text { Escasez de vegetación arbustiva y de fauna. } \\
\text { Actividades: andinismo, escalada en roca, } \\
\text { escalada en hielo, alta montaña, esquí de } \\
\text { montaña. }\end{array}$ \\
\hline
\end{tabular}

Fuente: Adaptado de (McColl, R., 2015)

Con base en la clasificación de una montaña de la tabla 3, se presenta el cuadro de montañas que se encuentran en el Ecuador, clasificadas de acuerdo a su nombre, altitud, ubicación, cordillera y nivel de dificultad. 
Tabla 5. Clasificación de las montañas del Ecuador

\begin{tabular}{|c|c|c|c|c|c|}
\hline $\mathbf{N}^{\circ}$ & Nombre & Altitud & Ubicación & Cordillera & Nivel \\
\hline 1 & Volcán Ilalo & 3.169 m.s.n.m. & Pichincha & Región Interandina & Baja \\
\hline 2 & Cerro de Callo & 3.169 m.s.n.m. & Cotopaxi & Región Interandina & Baja \\
\hline 3 & Volcán Casitagua & 3.200 m.s.n.m. & Pichincha & Occidental & Baja \\
\hline 4 & Volcán Cunrru & 3.305 m.s.n.m. & Imbabura & Región Interandina & Baja \\
\hline 5 & Volcán Pululahua & 3.336 m.s.n.m. & Pichincha & Occidental & Baja \\
\hline 6 & Volcán Pangaladera & 3.340 m.s.n.m. & Imbabura & Región Interandina & Baja \\
\hline 7 & Volcán Cuicocha & 3.377 m.s.n.m. & Imbabura & Occidental & Baja \\
\hline 8 & Volcán Pambamarca & 3.471 m.s.n.m. & Pichincha & Oriental & Baja \\
\hline 9 & Volcán Reventador & 3.485 m.s.n.m. & Sucumbíos - Napo & Oriental & Baja \\
\hline 10 & Cerro Putzalahua & 3.523 m.s.n.m & Cotopaxi & Oriental & Baja \\
\hline 11 & Volcán Coturco & 3.587 m.s.n.m. & Pichincha & Oriental & Baja \\
\hline 12 & Volcán Llimpi & 3.732 m.s.n.m. & Tungurahua & Región Interandina & Baja \\
\hline 13 & Volcán Ushnirumi & 3.776 m.s.n.m. & Imbabura & Occidental & Baja \\
\hline 14 & Volcán Sumaco & 3.828 m.s.n.m. & Napo - Orellana & Oriental & Baja \\
\hline 15 & Volcán Ninahuilca & 3.830 m.s.n.m. & Pichincha & Occidental & Baja \\
\hline 16 & Volcán Quilotoa & 3.910 m.s.n.m. & Cotopaxi & Occidental & Baja \\
\hline 17 & Volcán Santa Cruz & 3.950 m.s.n.m. & Pichincha - Cotopaxi & Región Interandina & Baja \\
\hline 18 & Volcán Punalica & 3.990 m.s.n.m. & Chimborazo & Occidental & Baja \\
\hline 19 & Volcán Cusin & 4.012 m.s.n.m. & Pichincha - Imbabura & Región Interandina & Media \\
\hline 20 & Volcán Sagoatoa & 4.153 m.s.n.m. & Tungurahua & Occidental & Media \\
\hline 21 & Volcán Pasochoa & 4.200 m.s.n.m. & Pichincha & Región Interandina & Media \\
\hline 22 & Volcán Mojanda & 4.290 m.s.n.m. & Pichincha - Imbabura & Región Interandina & Media \\
\hline 23 & Volcán Igualata & 4.430 m.s.n.m. & Tungurahua & Región Interandina & Media \\
\hline 24 & Volcán Pan de Azucar & 4.445 m.s.n.m. & Napo & Suboriental & Media \\
\hline 25 & Volcán Puntas & 4.452 m.s.n.m. & Pichincha & Oriental & Media \\
\hline 26 & Volcán Atacazo & 4.457 m.s.n.m. & Pichincha & Occidental & Media \\
\hline 27 & $\begin{array}{l}\text { Volcán Cerro Negro de } \\
\text { Mayasquer }\end{array}$ & 4.470 m.s.n.m. & Carchi & Occidental & Media \\
\hline 28 & Volcán Chacana & 4.500 m.s.n.m. & Napo & Real & Media \\
\hline 29 & Volcán Yanahurco & 4.535 m.s.n.m. & Imbabura & Occidental & Media \\
\hline 30 & Volcán Imbabura & 4.610 m.s.n.m. & Imbabura & Región Interandina & Media \\
\hline 31 & Volcán Sarahurco & 4.676 m.s.n.m. & Pichincha & Oriental & Media \\
\hline 32 & Volcán Rucu Pichincha & 4.696 m.s.n.m. & Pichincha & Occidental & Media \\
\hline 33 & Volcán Rumiñahui & 4.722m.s.n.m. & Pichincha - Cotopaxi & Región Interandina & Media \\
\hline 34 & Volcán Chiles & 4.748 m.s.n.m. & Carchi & Occidental & Media \\
\hline 35 & Volcán Corazón & 4.790 m.s.n.m. & Pichincha & Occidental & Media \\
\hline 36 & Volcán-Guagua Pichincha & 4.794 m.s.n.m. & Pichincha & Occidental & Media \\
\hline 37 & Volcán Cubilche & 4.826 m.s.n.m. & Imbabura & Región Interandina & Media \\
\hline 38 & Volcán Sincholagua & 4.919 m.s.n.m. & Pichincha & Occidental & Media \\
\hline 39 & Volcán Quilindaña & 4.919 m.s.n.m. & Cotopaxi & Oriental & Media \\
\hline 40 & Volcán Cotacachi & 4.939 m.s.n.m. & Imbabura & Occidental & Media \\
\hline 41 & Volcán Tungurahua & 5.016 m.s.n.m. & Tungurahua & Oriental & Alta \\
\hline 42 & Volcán Carihuairazo & 5.020 m.s.n.m. & Tungurahua & Occidental & Alta \\
\hline 43 & Volcán Iliniza Norte & 5.125 m.s.n.m. & Cotopaxi & Occidental & Alta \\
\hline 44 & Volcán Iliniza Sur & 5.226 m.s.n.m. & Cotopaxi & Occidental & Alta \\
\hline 45 & Volcán Altar & 5.319 m.s.n.m. & Chimborazo & Oriental & Alta \\
\hline
\end{tabular}




\begin{tabular}{llllll}
\hline 46 & Volcán Sangay & 5.320 m.s.n.m. & Morona Santiago & Oriental & Alta \\
\hline $\mathbf{4 7}$ & Volcán Antisana & 5.758 m.s.n.m. & Pichincha - Napo & Oriental & Alta \\
\hline $\mathbf{4 9}$ & Volcán Cayambe & 5.790 m.s.n.m. & Pichincha - Imbabura & Oriental & Alta \\
\hline 49 & Volcán Cotopaxi & 5.897 m.s.n.m. & Cotopaxi & Oriental & Alta \\
\hline $\mathbf{5 0}$ & Volcán Chimborazo & 6.384 m.s.n.m. & Chimborazo & Occidental & Alta
\end{tabular}

¿Cómo considera que un turista debe empezar en el montañismo? Debe iniciar teniendo pasión por la naturaleza, debe gustarle las montañas, se sugiere estudiar el comportamiento climático y entender los riesgos que se corre en el proceso de hacer cumbre. Posteriormente debe autoevaluarse físicamente, pues para ello si no práctica algún deporte, debe iniciar realizando caminatas cada vez más extensas y de dificultad moderable en baja montaña (se recomienda hacerlo acompañado de alguna persona con experiencia en montañismo), y autoevaluarse periódicamente sus mejorías o descubrir sus debilidades (médicas, físicas, psicológicas y técnicas), y si ya cree que está preparado para hacer cumbre, se recomienda hacer caso a la normativa y contratar a un guía especializado en alta montaña y cumplir con el proceso de aclimatación y manejo de implementos y equipos necesarios para la práctica de este deporte.

¿Qué ejercicios recomienda realizar a una persona que se va a involucrar en el montañismo? Se recomienda antes de iniciar cualquier tipo deporte, realizarse exámenes médicos para conocer el estado real de su salud. Dependiendo de la edad, su experiencia en actividades físicas y sus objetivos, pude iniciar con la práctica de senderismo en baja montaña, acampadas en la naturaleza, y hacer rutinario si es posible realizar ejercicio (trotar, gimnasio, ciclismo, entre otros) una hora por día. Además se recomienda ir adquiriendo y adaptándose a los equipos e implementos necesarios para la práctica del montañismo.

¿Considera $U d$. que el realizar un adecuado entrenamiento físico baste para ascender una montaña? En el montañismo, nosotros en calidad de guías hemos visto muchos casos de turistas con buen estado físico y hasta con buenos conocimientos técnicos en manejo de equipos e implementos, que ante las dificultades y retos de la montaña han desertado el ascenso, a veces incluso faltando pocos metros para hacer cumbre, principalmente esto sucede por la no preparación suficiente en la parte psicológica de un turista. El montañismo es un deporte que demanda de buna salud, buen estado físico, buenos conocimientos técnicos y sobre todo de concentración y objetivos claros.

\section{Identificación de variables psicológicas, físicas, médicas y técnicas}

Con base en la información proporcionada por los expertos, y revisión bibliográfica e información secundaria, se identificaron las variables; psicológicas, físicas, médicas y técnicas que forman parte del test psicofísico 
propuesto. A continuación se presenta la tabla dividida en; factores, variables, sub-variables y justificación:

Tabla 6. Tabla de Referencia de Variables Psicológicas, Físicas, Médicas y Técnicas para la práctica del Montañismo

\begin{tabular}{|c|c|c|c|}
\hline Factores & Variables & Sub variables & Justificación \\
\hline \multirow{4}{*}{ Psicológicas } & Tipo de tenciones & $\begin{array}{l}\text { Estrés, ansiedad, frustración } \\
\text { por: } \\
\text { - } \quad \text { Trabajo } \\
\text { - Hogar } \\
\text { - } \quad \text { Familia lejana } \\
\end{array}$ & $\begin{array}{l}\text { Evalúa el estado emocional de los } \\
\text { turistas y permite conocer la multi- } \\
\text { causalidad psicológica de su viaje. }\end{array}$ \\
\hline & Motivaciones & $\begin{array}{ll}\text { - } & \text { Nuevas experiencias } \\
\text { - } & \text { Perder el estrés } \\
\text { - } & \text { Salir de los } \\
\text { - } & \text { problemas } \\
& \text { Conocer nuevas } \\
& \text { amistades } \\
\text { - } & \text { Salir de la rutina }\end{array}$ & $\begin{array}{l}\text { Complementa la variable anterior para } \\
\text { conocer las expectativas del viaje de los } \\
\text { turistas. }\end{array}$ \\
\hline & Vértigo & $\begin{array}{ll}- & \text { Miedo } \\
\text { - } & \text { Nerviosismo } \\
\end{array}$ & $\begin{array}{llll}\text { Permite conocer la } & \text { debilidad } \\
\text { psicológica de los turistas. } & \\
\end{array}$ \\
\hline & Satisfacción & $\begin{array}{l}\text { Muy satisfecho por el } \\
\text { logro alcanzado } \\
\text { - Satisfecho si llego o } \\
\text { no } \\
\text { - Poco satisfecho por } \\
\text { no llegar }\end{array}$ & $\begin{array}{l}\text { Permite conocer el nivel de firmeza y } \\
\text { compromiso por cumplir objetivos. }\end{array}$ \\
\hline \multirow{5}{*}{ Físicas } & $\begin{array}{l}\text { Evaluación } \\
\text { cardio- } \\
\text { respiratoria }\end{array}$ & - Test de Cooper & $\begin{array}{l}\text { Evalúa la capacidad física, } \\
\text { cardiovascular y respiratoria de una } \\
\text { persona, llevándola a un punto cercano } \\
\text { al agotamiento. }\end{array}$ \\
\hline & $\begin{array}{l}\text { Capacidad } \\
\text { anaeróbica }\end{array}$ & - $\quad$ Test de Burpee & $\begin{array}{l}\text { Mide la resistencia anaeróbica latica, } \\
\text { que es la resistencia a esfuerzos de alta } \\
\text { intensidad en déficit de oxígeno con una } \\
\text { duración suficiente como para que se } \\
\text { produzca acumulación de lactato. }\end{array}$ \\
\hline & Flexibilidad & - $\quad$ Test de Wells & $\begin{array}{l}\text { Evalúa la elasticidad y movilidad de un } \\
\text { turista. }\end{array}$ \\
\hline & $\begin{array}{l}\text { Fuerzas motoras } \\
\text { superiores }\end{array}$ & - Fuerza de brazos & $\begin{array}{l}\text { Permite medir la elasticidad de la } \\
\text { musculatura isquiotibial (capacidad de } \\
\text { estiramiento). Ya que el cuerpo tiene } \\
\text { que estar apto ante movimientos } \\
\text { continuos y brucos a la vez en } \\
\text { momentos inesperados. }\end{array}$ \\
\hline & $\begin{array}{l}\text { Frecuencia } \\
\text { máxima }\end{array}$ & - Índice de Ruffier & $\begin{array}{l}\text { Mide la frecuencia cardiaca máxima de } \\
\text { una persona. }\end{array}$ \\
\hline
\end{tabular}




\begin{tabular}{|c|c|c|c|}
\hline & $\begin{array}{l}\text { Rutina de } \\
\text { ejercicio }\end{array}$ & - $\quad$ Peso & $\begin{array}{l}\text { El peso es un indicador de bienestar de } \\
\text { una persona debe estar desacuerdo a su } \\
\text { edad y talla. }\end{array}$ \\
\hline & Vicios & $\begin{array}{ll}\text { - } & \text { Alcohol } \\
\text { - } & \text { Cigarrillos } \\
\text { - } & \text { Sustancias } \\
& \text { alucinógenas }\end{array}$ & $\begin{array}{l}\text { Analiza el historial de mala salud en una } \\
\text { persona. }\end{array}$ \\
\hline \multirow{7}{*}{ Médicas } & $\begin{array}{l}\text { Problemas } \\
\text { cardiacos }\end{array}$ & $\begin{array}{l}\text { - } \text { Corazón } \\
\text { - } \text { Vasos sanguíneos } \\
\text { - } \text { Miocarditis } \\
\text { - } \\
\text { Probias coronarias } \\
\text { pericardio }\end{array}$ & $\begin{array}{l}\text { Es necesario identificar si las personas } \\
\text { tienen dichas enfermedades para evitar } \\
\text { problemas mayores en el ascenso. }\end{array}$ \\
\hline & $\begin{array}{l}\text { Problemas de } \\
\text { presión alta }\end{array}$ & $\begin{array}{l}\text { Dificultad para } \\
\text { respirar }\end{array}$ & $\begin{array}{l}\text { Permite determinar la capacidad física } \\
\text { cardiovascular y respiratoria de una } \\
\text { persona. }\end{array}$ \\
\hline & Dolores & $\begin{array}{ll} & \text { Cabeza } \\
\text { - } & \text { Estomago } \\
\text { - } & \text { Huesos } \\
\text { - } & \text { Pecho } \\
\end{array}$ & $\begin{array}{l}\text { Es importante saber si la persona } \\
\text { presenta síntomas de dolor en las } \\
\text { diferentes partes, podría complicarse } \\
\text { mucho más durante la actividad. }\end{array}$ \\
\hline & Mareo & $\begin{array}{ll} & \text { Alto } \\
\text { - } & \text { Leve } \\
\end{array}$ & Aumentará en la altura. \\
\hline & Alucinaciones & $\begin{array}{ll}\text { - } & \text { Visuales } \\
\text { - } & \text { Auditivas } \\
\end{array}$ & Puede complicar al equipo. \\
\hline & Vomito & - $\quad$ Náuseas & Aumentará en la altura. \\
\hline & Signos vitales & - & $\begin{array}{l}\text { Es importante verificar los cuatro signos } \\
\text { vitales de la persona, de esta manera se } \\
\text { asegura su estado de salud y continuar } \\
\text { con la actividad ejercitándose mucho } \\
\text { más. }\end{array}$ \\
\hline \multirow{7}{*}{ Técnicas } & Clima & - $\quad$ Lluvia & Permite tener un panorama de la \\
\hline & & $\begin{array}{ll}\text { - } & \text { Calor } \\
\text { - } & \text { Frio } \\
\text { - } & \text { Neblina }\end{array}$ & $\begin{array}{c}\text { Actividad a realizar y el equipo } \\
\text { necesario a usar. }\end{array}$ \\
\hline & Factor $3 \times 3$ & $\begin{array}{ll}\text { - } & \text { Terreno } \\
\text { - } & \text { Equipo } \\
\text { - } & \text { Clima } \\
\end{array}$ & Permite alcanzar los objetivos trazados. \\
\hline & $\begin{array}{l}\text { Métodos de } \\
\text { orientación }\end{array}$ & $\begin{array}{ll}\text { - } & \text { Carta topográfica } \\
\text { - } & \text { Brújula } \\
\text { - } & \text { GPS } \\
\end{array}$ & $\begin{array}{l}\text { Es de vital importancia que las personas } \\
\text { sepan orientarse en la montaña }\end{array}$ \\
\hline & $\begin{array}{l}\text { Equipo adecuado } \\
\text { según la actividad }\end{array}$ & $\begin{array}{l}\text { Linterna frontal, casco, gafas, } \\
\text { piolet, arnés, estacas de nieve, } \\
\text { cuerda, mosquetones etc. }\end{array}$ & $\begin{array}{l}\text { Para la práctica de montañismo, al } \\
\text { menos de alta montaña, debe saber usar } \\
\text { el equipo. }\end{array}$ \\
\hline & $\begin{array}{l}\text { Estaciones en } \\
\text { nieve y roca }\end{array}$ & - & $\begin{array}{l}\text { Debe conocer las técnicas de las } 2 \\
\text { estaciones. }\end{array}$ \\
\hline & Equipo técnico & $\begin{array}{ll}- & \text { Piolet } \\
\text { - } & \text { Crampones } \\
\text { - } & \text { Reveso } \\
\end{array}$ & $\begin{array}{l}\text { Para ascender deben saber usar el } \\
\text { equipo. }\end{array}$ \\
\hline
\end{tabular}




\begin{tabular}{|c|c|c|l|l|}
\hline & - & $\begin{array}{l}\text { Recuperación de una } \\
\text { Reacción en caso } \\
\text { de accidente }\end{array}$ & persona herida & $\begin{array}{l}\text { Permite conocer la capacidad de cada } \\
\text { persona ante momentos inesperados: } \\
\text { saber cómo actuar, como ayudar, como } \\
\text { aportaría ante la situación. }\end{array}$ \\
\hline
\end{tabular}

\section{Test}

Con base en el análisis de la información segundaria y primaria proporcionada por los expertos y el cuadro de variables de la tabla 6 . Se diseñó el test psicofísico, que evalúa el estado físico, médico, psicológico y técnico de los turistas, previo al proceso de aclimatación y ascenso a la montaña. El test cuenta con preguntas que según los datos obtenidos son de mayor importancia para la determinación del perfil de un turista de alta, media o baja montaña, cabe resaltar que, el test psicofísico ha sido validado por los expertos que proporcionaron la información en el presente estudio.

Datos del Turista:

Nombre y apellido:

Lugar de procedencia:

Genero: Edad:

Instrucciones:

Responda de forma responsable y sincera cada una de las preguntas:

¿Usted consume algún tipo de sustancias?

Si

No

Alcohol

Cigarrillo

Sustancias Alucinógenas

Otros:

¿Padece Ud. de problemas cardiacos?

SI No

¿Tiene problemas de presión alta?

Si No

¿Ha presentado usted algún síntoma al estar en las alturas?

Si

No

Dolor de cabeza

Dolor de estómago

Mareo

¿Realiza algún tipo de actividad?

Si

No

A veces

Natación

Caminata

Trail

Ciclismo

\section{Preguntas Psicológicas}

¿Ud. Siente algún tipo de tensión que le causa estrés, ansiedad

Si No Tal vez

o frustración?

Trabajo

Hogar

Familia lejana 
Otros:

¿Cuál sería su motivación para lanzarse a experimentar

Si

No

Tal vez nuevas cosas?

Nuevas experiencias

Perder el estrés

Salir de los Problemas

Conocer nuevas amistades

Salir de la rutina

Otros:

¿Le gustaría ascender a un nevado?

Si No Tal vez

¿Sufre de vértigo?

Si No Tal vez

¿Cuándo conoce alguna persona por primera vez, Ud?

Siempre A veces Nunca

Interactúa enseguida

Toma su tiempo para conocerla de lejos

No dice, ni aporta nada

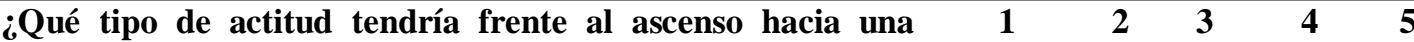
cumbre?

Emoción

Interés intelectual

Felicidad

Nerviosismo

¿Qué sucede en usted frente al hecho de lograr culminar la meta de llegar a la cumbre?

Muy satisfecho por el logro alcanzado

Satisfecho si llego o no

Poco satisfecho por no llegar

Preguntas Técnicas

¿Cuánto tiempo tarda usted en adaptarse a un tipo de clima?

2 a 5 días

1 semana

2 semanas

3 semanas

Mas:

¿Qué instrumentos utilizaría Ud para orientarse en el campo?

Brújula

Carta topográfica

GPS

Aplicaciones de Smartphone

¿Conoce Ud. el equipo adecuado para la actividad de campamentación? Mencione 10:

¿Conoce el equipo adecuado para la actividad de media montaña? Mencione 5:

¿Conoce el equipo adecuado para la actividad de alta montaña? Mencione 18:

¿Puede armar algún tipo de estación?

En roca 
En hielo

Ambas

¿Conoce Ud. el manejo de equipo técnico?

Piolet

Crampones

Reverso

¿En caso de un accidente Ud. Está en la capacidad de?

La recuperación de una persona herida

Auto rescate

Auto detención

Las tres

¿Cuántos nudos para realizarlos con soga conoce? Mencione 6:

Preguntas Físicas

Test de Cooper (evaluación cardio respiratoria)

La actividad consiste en recorrer la mayor cantidad de metros en 12 minutos

Metros recorridos

\section{Test de Burpee (capacidad anaeróbica)}

La actividad consiste en ponerse de pie, seguidamente colocarse en cunclillas, colocar los pies hacia atrás sosteniéndose con las manos, regresar nuevamente en cunclillas y saltar.

Cantidad

\section{Test de Wells (Elasticidad o flexibilidad)}

Consiste en agacharse por un tiempo de 5 segundos y ver hasta que medida llegan los dedos de las manos.

\section{Medida}

\section{Test de fuerza de brazos}

La actividad consiste en la mayor cantidad de flexiones de pecho que se pueda realizar por 1 minuto

Cantidad

\section{Índice de Ruffier (mide la frecuencia cardiaca máxima)}

Visual

\section{Color de piel}

Si se observa un color de piel pálido durante una ascensión se debe a la falta de oxígeno en el organismo por lo que es mejor detenerse y respirar de manera profunda, hasta controlar la respiración.

\section{Respiración}

Si se observa que el turista tiene la respiración muy agitada es mejor detenerse y hacer que el turista descanse, tome agua y se recupere ya que corre peligro de un paro cardiaco.

Respiración durante ejercicio 40 a 60 veces x min.
Táctil

\section{Pulso Normal}

$60-100$

Pulsaciones por minuto:

Formula de medición:

FC Máxima $=(220-$ edad $)$

\section{Ponderación del test}

Los siguientes datos influyen en el estado emocional y físico de los turistas, al momento de practicar montañismo, senderismos y 
campamentación. A continuación se describe la metodología de ponderación de los componentes-factores del test psicofísico:

Medidas Médicas. Con el peso en $\mathrm{Kg}$ y la talla se mide el índice de masa corporal (IMC) de un turista, este índice se obtiene dividiendo el peso (en Kilogramos) por el cuadrado de la estatura en metros (la estatura multiplicada por sí misma): Peso $(\mathrm{Kg}) /$ Estatura $(\mathrm{m}) 2=$ I.M.C. Con base al IMC podemos tener una idea más precisa, aunque no absoluta, de si tenemos un peso adecuado o si estamos en una categoría de sobrepeso o incluso de obesidad. La misma no resulta exacta para personas muy musculosas o mujeres embarazadas (Mimenza, O. C., s/f).

Tabla 7. Tabla de referencia e interpretación

\begin{tabular}{ccc}
\hline Valor & Clasificación & Características \\
\hline 0 a 5 & Delgadez III & Enfermedades degenerativas. \\
\hline $\mathbf{5}$ a 10 & Delgadez II & Anorexia , Bulimia \\
\hline $\mathbf{1 0}$ a & Delgadez I & $\begin{array}{c}\text { Trastornos Digestivos, } \\
\text { debilidad, fatiga crónica. }\end{array}$ \\
\hline $\mathbf{1 8 . 5}$ & Peso Normal & $\begin{array}{c}\text { Estado normal, buen nivel de } \\
\text { energía, vitalidad. }\end{array}$ \\
\hline $\mathbf{2 4 . 9}$ & & $\begin{array}{c}\text { Fatiga, enfermedades } \\
\text { digestivas. }\end{array}$ \\
$\mathbf{2 9 . 9}$ & Sobrepeso & $\begin{array}{c}\text { Diabetes, hipertensión, } \\
\text { enfermedades }\end{array}$ \\
$\mathbf{3 0}$ a & Obesidad I & cardiovasculares \\
\hline 34.9 & & $\begin{array}{c}\text { Diabetes, posible cáncer, } \\
\text { angina de pecho. }\end{array}$ \\
\hline $\mathbf{3 5}$ a & Obesidad II & Falta de aire, cáncer, \\
$\mathbf{3 9 . 9}$ & Oiscriminación social. \\
\hline 40 o + & Obesidad III & \\
\hline
\end{tabular}

Fuente: Adaptado de (Mimenza, O. C., s/f)

Factores psicológicos. Control del estrés: depende de las características de respuesta del turista (concentración, confianza, tensión) en relación a las demandas y situaciones potencialmente estresantes que pueden provocar la práctica del montañismo. Una puntuación alta en esta escala indica que el turista dispone de recursos psicológicos para controlar el estrés relacionado con su participación en el montañismo. Motivación: el interés de los turistas por preparase física y técnicamente para la consecución de metas $\mathrm{u}$ objetivos (hacer cumbre), la importancia del turista en relación con otras actividades y facetas de su vida, relación coste/beneficio que para el turista tiene su el montañismo. Cohesión de equipo: se refiere a la integración del turista en el equipo o grupo de montañismo; relación interpersonal con los miembros del equipo, nivel de satisfacción al trabajar con los otros miembros del equipo, actitud más o menos individualista en relación con el grupo y en 
especial la importancia que se le conceda al espíritu de equipo (ANBCR, 2010).

Conocimientos técnicos. Orientación: en la montaña independientemente de la actividad que se practique, es indispensable saber orientarse y conocer en todo momento la posición sobre el terreno, por tanto, es necesario disponer de un mínimo de herramientas de las que es necesario conocer bien su uso: mapas, brújula y altímetro (Homs, 2012). La lectura de los mapas topográficos está al alcance de todos y aunque requiere un pequeño esfuerzo inicial nos aportara después un cumulo de satisfacciones. La orientación aproximada con la ayuda del sol es fácil, pero en caso de mal tiempo, la brújula y el altímetro son indispensables. Escalada y rappel, ascenso o descenso por cuerda: consiste en técnicas de ascenso y descenso controlado, realizada por medio de una cuerda doble. Generalmente se utilizan sogas de grandes longitudes $(60-80 \mathrm{~m})$, (Hgmexico, 2017). Técnicas indispensables para los turistas que deseen hacer cumbre. Detención con piolet: siempre que se lleve un piolet en la mano, y se dé la caída o deslizamiento por la nieve, se procederá a colocar al piolet en posición pioletancla, y sin importar la posición en la que nos encontremos, se dará un giro durante la caída a fin de situarse con la cara a la pendiente con el fin de clavar el pico del piolet en la misma (Galeon, H., 2013).

Equipo técnico. El material debe encontrarse en perfecto estado; botiquín personal, medios de señalización (lámparas, bengalas, silbatos, ropa fluorescente, etc.). Igual debe estar adaptado a la disciplina practicada y a las condiciones más desfavorables posibles en la montaña: niebla, viento, precipitaciones, humedad, alternancia de sol y sombra, diferencias entre frio y calor que no son comparables a las que se encuentran en las llanuras (Larrosa, 2014). Linterna frontal: debe ser de plástico, robusta y lo más estanca posible. Son muy interesantes los modelos que pueden conectarse a las pilas, que van en un bolsillo interior, mediante un cable, pues éstas duran más al llevarlas calientes. Es conveniente que la misma linterna lleve algún alojamiento para bombillas de repuesto. Casco: imprescindible en alta montaña, tiene que ser ligero, sólido, amplio, para poder llevarlo con gorros, y de fácil colocación. Gafas: imprescindibles en la nieve si no queremos que nos afecte la "ceguera de las nieves", tienen que llevar el mayor factor de protección en las lentes, y que no dejen traspasar los rayos ultravioletas, algunos modelos llevan protecciones laterales para que no penetre la luz y otros son totalmente envolventes. Piolet: la longitud de este irá en función del uso que vayamos a darle y de las pendientes que tengamos que afrontar, pues unos $60 \mathrm{~cm}$. de longitud son suficientes para recorridos clásicos con inclinaciones medias de hasta $45^{\circ}$ ó incluso $50^{\circ}$, a partir de aquí se hace necesario que el piolet se acorte hasta los $50 \mathrm{~cm}$. para mayores inclinaciones, usaremos una dragonera que nos una al piolet por la muñeca, disponiéndola según el modelo y las preferencias 
del usuario, siempre y cuando nos permita asir el piolet de forma que podamos realizar cualquier técnica y tipo de seguro con el mismo. El arnés: brinda protección en caso de una caída, hoy en día existe una gran diversidad de modelos en el mercado, y en la mayoría de los casos son totalmente fiables, sobre todo hay que mirar que lleven el Label U.I.A.A. de seguridad. Crampones: pueden ser rígidos o articulados, de 10, 12 ó 14 puntas, con la clásica correa para atarlos a la bota o con fijación automática tipo esquí. En la actualidad, los semirígidos de 12 puntas y con fijación semi-automática se pueden considerar los más prácticos para todos los terrenos, siempre que se calcen con botas de plástico. Estacas de nieve: son perfiles metálicos largos y ligeros que usan en nieve para montar reuniones y fijar el rapel. Tornillos: son el mejor método de seguro en nieve muy dura y hielo, existiendo varios tipos. Los más comunes son los troncocónicos, de diámetro progresivo con forma de espina, que se utilizan para hielo muy duro, y que se colocan a martillazos y girando al final la cabeza del tornillo $1 / 4$ de vuelta para su correcto bloqueo en el hielo, y los tubulares, con muchos y diferentes diseños, son cilíndricos, con rosca y huecos en el centro, colocándose a rosca una vez que han "mordido" en la nieve dura o el hielo. Los mosquetones: son unas piezas metálicas cuyo objetivo es el de unir los diferentes elementos utilizados en el acenso o descenso de una montaña como: descensores, aseguradores mecánicos, cuerdas, etc. Normalmente, se fabrican para resistir cargas de 2.000 a 3.000 Kg., longitudinalmente y unos 500 a $900 \mathrm{Kg}$., transversalmente. Cuerda: la diferencia entre cuerdas dinámicas y cuerdas auxiliares reside en que las primeras deben garantizar la seguridad en caso de caída y las segundas mantener la carga. Las cuerdas auxiliares o estáticas poseen una elevada resistencia a la rotura, pero son incapaces de absorber adecuadamente las fuerzas generadas en una caída. Los cordinos: son cuerdas más finas, para los cordinos rigen los siguientes criterios de selección: alta resistencia a la tracción, alargamiento reducido, bajo peso, polivalencia, flexibilidad equilibrada, resistencia a los rayos ultravioletas y obviamente resistencia a la abrasión. Los cordinos son económicos y muy útiles. Se utilizan esencialmente para anillos, nudos prusik, fisureros y cuerdas auxiliares. Las cintas: son productos textiles de forma plana o tubular. La forma plana de las cintas es ventajosa para el cuerpo humano, al repartir el peso sobre las extremidades y la cintura (confección de arneses), además de facilitar su cosido. Las cintas se utilizan sobre todo para arneses, cintas exprés, anillos, porta-materiales, estribos, etc. Importante: dada la tendencia que experimenta la cinta a resbalar sobre sí misma bajo grandes pesos, todos los nudos que se utilizan normalmente con las cuerdas son inválidos para las cintas (Vidales,H; Vidales, G., 2015). (SENAGUA, 2015) (Posada, 2013)

Vestimenta: se debe llevar cumbre bocas y nariz, trozo de tela en forma de tubo, reconocida por varios deportistas, sirve para apaciguar el calor o secar 
el sudor y en invierno para protegernos del frio, el viento y la lluvia utilizada de varias formas como: cobertor de cuello, cobertor de cuello, orejas y nariz, gorro y muñequera. La $1^{\mathrm{a}}$ capa de vistimenta es la que va en contacto con la piel, su función es tanto el abrigo como eliminar la humedad de la transpiración, debe ser por lo tanto de tejidos que no absorban agua y muy transpirables. La $2^{a}$ capa de vestimenta tiene como principal función de abrigar el cuerpo sin olvidar la transpiración, son prendas más voluminosas que se basan en la retención del aire caliente generado por el cuerpo, pueden ser de diversos materiales (forro polar, fleece, fibra, pluma, etc.). La $3^{\text {a }}$ capa de vestimenta son las prendas que llevamos en contacto con el exterior cuando las condiciones son severas. Su función es la de aislarnos del viento y de la humedad (nieve ó agua) para mantener el calor generado por el cuerpo. Gorros son fundamentales para proteger la cabeza, ya sea del sol ó del frío (la mayor parte del calor que perdemos es por la cabeza), en verano, llevaremos una gorra con visera que nos proteja del sol, y en invierno un gorro de abrigo con orejeras, y a ser posible con una pequeña visera que nos proteja igualmente del sol y el viento. Guantes, llevaremos siempre dos pares, un par fino como capa interior, que nos servirá para realizar operaciones delicadas, y otro par con membrana cortaviento y forro térmico, que debe llevar una cinta larga que nos permita soltarlos y que queden colgando de la muñeca para no perderlos. Polainas, son imprescindibles en invierno para que no nos entre la nieve dentro de la bota. Se fabrican en materiales impermeables y anti-desgarro. El calzado, existen una gran variedad de botas de montaña, con diferentes materiales y diseños, para la práctica del alpinismo en invierno hay dos tipos de botas, las rígidas y las semirrígidas, a las primeras pertenecen las botas de carcasa plástica, que se generalizaron en los años 80 y 90, siendo aún hoy día la bota más apropiada en condiciones de mucha nieve y frío, sobre todo, si la actividad es de más de un día, pues llevan en su interior un botín de material muy aislante que es el encargado de mantener los pies calientes. La mochila, actualmente existe una gran variedad de mochilas para la montaña, tanto de excursionismo como de alta montaña (Vidales, H; Vidales, ., 2015).

Preguntas físicas. Test de Cooper. Es una prueba de exigencia, donde la distancia y el tiempo sugeridos buscan poner al máximo la capacidad física, cardiovascular y respiratoria de una persona, llevándola a un punto cercano al agotamiento (Testworld, 2019).

Tabla 6. Tabla de referencia e interpretación

\begin{tabular}{|c|c|c|c|c|c|}
\hline \multicolumn{6}{|c|}{ Test de Cooper } \\
\hline Categoría & & $\frac{\text { Menos de 30 }}{\text { años }}$ & 30 a 39 años & $\underline{40 \text { a } 49 \text { años }}$ & 50 años o más \\
\hline \multirow[t]{2}{*}{ Muy mala } & $\mathrm{M}$ & Menos de $1600 \mathrm{~m}$ & Menos de $1500 \mathrm{~m}$ & Menos de $1400 \mathrm{~m}$ & Menos de $1300 \mathrm{~m}$ \\
\hline & $\mathrm{F}$ & Menos de $1500 \mathrm{~m}$ & Menos de $1400 \mathrm{~m}$ & Menos de $1200 \mathrm{~m}$ & Menos de $1100 \mathrm{~m}$ \\
\hline \multirow[t]{2}{*}{ Mala } & M & 1600 a $2199 \mathrm{~m}$ & 1500 a $1999 \mathrm{~m}$ & 1400 a 1699 m & 1300 a $1599 \mathrm{~m}$ \\
\hline & $\mathrm{F}$ & 1500 a $1799 \mathrm{~m}$ & 1400 a $1699 \mathrm{~m}$ & 1200 a $1499 \mathrm{~m}$ & 1200 a $1399 \mathrm{~m}$ \\
\hline
\end{tabular}




\begin{tabular}{|c|c|c|c|c|c|}
\hline \multirow[t]{2}{*}{ Regular } & $\mathrm{M}$ & 2200 a $2399 \mathrm{~m}$ & 2000 a $2299 \mathrm{~m}$ & 1700 a $2099 \mathrm{~m}$ & 1600 a 1999 m \\
\hline & $\mathrm{F}$ & 1800 a $2199 \mathrm{~m}$ & 1700 a 1999 m & 1500 a $1899 \mathrm{~m}$ & 1400 a $1699 \mathrm{~m}$ \\
\hline \multirow[t]{2}{*}{ Buena } & $\mathrm{M}$ & 2400 a $2800 \mathrm{~m}$ & 2300 a $2700 \mathrm{~m}$ & 2100 a $2500 \mathrm{~m}$ & 2000 a $2400 \mathrm{~m}$ \\
\hline & $\mathrm{F}$ & 2200 a $2700 \mathrm{~m}$ & 2000 a $2500 \mathrm{~m}$ & 1900 a $2300 \mathrm{~m}$ & 1700 a $2200 \mathrm{~m}$ \\
\hline \multirow[t]{2}{*}{ Excelente } & M & Más de 2800 m & Más de 2700 m & Más de 2500 m & Más de 2400 m \\
\hline & $\mathrm{F}$ & Más de $2700 \mathrm{~m}$ & Más de $2500 \mathrm{~m}$ & Más de $2300 \mathrm{~m}$ & Más de $2200 \mathrm{~m}$ \\
\hline
\end{tabular}

Test de Burpee. Es un test que ayuda a medir la resistencia anaeróbica latica, que es la resistencia a esfuerzos de alta intensidad en déficit de oxígeno con una duración suficiente como para que se produzca acumulación de lactato (Testsworld, 2019).

Tabla 7. Tabla de referencia de interpretación

\begin{tabular}{|c|c|c|}
\hline \multicolumn{3}{|c|}{ Test de Burpee } \\
\hline \multirow[t]{2}{*}{ Categoría } & \multicolumn{2}{|c|}{ Cantidad de saltos } \\
\hline & Hombres & Mujeres \\
\hline Malo & Menos de 25 saltos & Menos de 20 saltos \\
\hline Normal & De 25 a 35 saltos & De 20 a 30 saltos \\
\hline Bueno & 35 a 45 saltos & De 20 a 40 saltos \\
\hline Muy Bueno & De 45 a 55 saltos & 40 a 50 saltos \\
\hline Excelente & Más de 55 saltos & Más de 50 saltos \\
\hline
\end{tabular}

Fuente: Adaptado de (Testworld, 2019)

Test de Wells. Este test nos ayuda a medir la cualidad física de la flexibilidad, mide la elasticidad de la musculatura isquiotibial (capacidad de estiramiento), (Contreras, 2011).

Tabla 8. Tabla de referencia e interpretación Test de Wells

\begin{tabular}{|c|c|c|}
\hline \multicolumn{3}{|c|}{ Test de Wells } \\
\hline \multirow[t]{2}{*}{ Categoría } & \multicolumn{2}{|c|}{ Nivel de Estiramiento } \\
\hline & Hombres & Mujeres \\
\hline Muy pobre & Menos de $-20 \mathrm{~cm}$ & Menos de $-15 \mathrm{~cm}$ \\
\hline Pobre & De $-9 a-19 \mathrm{~cm}$ & De -8 a $-14 \mathrm{~cm}$ \\
\hline Deficiente & $\mathrm{De}-1 \mathrm{a}-8 \mathrm{~cm}$ & De 0 a $-7 \mathrm{~cm}$ \\
\hline Promedio & De 0 a $5 \mathrm{~cm}$ & De 1 a $10 \mathrm{~cm}$ \\
\hline Buena & De 6 a $16 \mathrm{~cm}$ & De 11 a $20 \mathrm{~cm}$ \\
\hline Excelente & De 17 a $27 \mathrm{~cm}$ & De 21 a $30 \mathrm{~cm}$ \\
\hline Superior & Más de $27 \mathrm{~cm}$ & Más de $30 \mathrm{~cm}$ \\
\hline
\end{tabular}

Fuente: Adaptado de (Contreras, E., 2011)

Test de Fuerza de Brazos. Se debe realizar la mayor cantidad de flexiones de brazos (de pecho) que puedas durante un minuto y anotar el resultado final (Gutierrez, C., 2014).

Tabla 9. Tabla de referencia e interpretación Fuerza de Brazos

\section{Fuerza de brazos}




\begin{tabular}{|c|c|c|c|c|c|}
\hline \multirow[t]{2}{*}{ Género } & \multicolumn{5}{|c|}{ Flexiones de pecho } \\
\hline & Muy bueno & Bueno & Normal & Bajo & Muy bajo \\
\hline M & Más de 40 & De 25 a 40 & De 15 a 24 & De 5 a 14 & Menos de 5 \\
\hline $\mathbf{F}$ & Más de 30 & De 20 a 30 & De 12 a 19 & De 5 a 11 & Menos de 4 \\
\hline
\end{tabular}

Fuente: Adaptado de (Gutierrez, C., 2014)

Índice de Ruffier. Para medir la frecuencia cardiaca máxima. Se utiliza la siguiente formula:

Tabla 12. Tabla de referencia e interpretación Índice de Ruffier

\begin{tabular}{c}
$\frac{\text { Frecuencia cardiaca máxima }}{\underline{\text { Pulsaciones }}}$ \\
$\underline{\text { Hombre }} \underline{\text { Mujer }} \underline{\underline{\text { MCm }}=(220-\text { edad }) \quad \mathrm{FCm}=(210-\text { edad })}$ \\
\hline
\end{tabular}

Fuente: Adaptado de (Gutierrez, C., 2014)

\section{Conclusiones}

Mediante la aplicación de la entrevista a los expertos y la recopilación de datos en diversas fuentes bibliográficas se pudo obtener la caracterización de 4 factores claves para la práctica del montañismo: conocimientos físicos, médicos, psicológicos y técnicos. Conocimientos necesarios para el desarrollo de un test evaluativo que permita medir las condiciones físicas y psicológicas del turista. Además los guías de alta montaña poseen conocimiento de las técnicas antes mencionadas y mediante ello practican el deporte de montaña con los turistas, sin asegurar que el turista realmente este apto para practicarlo. El diseño metodológico del test evaluativo se constituyó de: 5 preguntas médicas, 7 preguntas psicológicas, 9 preguntas técnicas y 5 preguntas físicas, dando un total de 26 preguntas. Cada factor de evaluación del test, posee su respectiva metodología de ponderación, permitiendo evaluar la condición física, mental y emocional del turista.

La propuesta metodológica del presente documento, consiste en aplicar un test psicofísico previo al proceso de aclimatación y ascenso a las montañas, que evalúa las condiciones físicas y psicológicas de los turistas, a través de la ponderación de factores: físico, médico, psicológico y técnico. Obteniendo como resultado la capacidad de adaptabilidad ante posibles percances en la montaña. Con base en los resultados de la ponderación de los factores antes mencionados, la presente propuesta metodológica clasifica a los turistas de la siguiente manera; alta montaña debe obtener una ponderación de excelente, media montaña debe obtener una ponderación de muy bueno y bueno, y baja montaña debe obtener una ponderación de muy malo, malo y regular. 


\section{Recomendaciones}

Se recomienda posterior a la aplicación del test psicofísico proceder a la fase de aclimatación, según lo establezca la persona a cargo (guía especializado), por lo general a los turistas que presenten resultados excelentes en el test psicofísico, pueden realizar la fase de aclimatación en 4 ascensos en medía montaña, seleccionando montañas que presenten dificultades similares a las de alta montaña, con la finalidad de fortalecer sus condiciones físicas y conocimientos técnicos.

Incentivar a los guías de mayor trayectoria y experiencia en el montañismo, se involucren y aporten con sus conocimientos (conocimientos físicos, médicos, psicológicos, técnicos) en futuras investigaciones de esta naturaleza. Con la finalidad de mitigar percances en las montañas por impericia.

A más de los factores y variables estudiadas en el presente documento, se recomienda a los turistas realizarse exámenes médicos generales antes de practicar montañismo y conocer con exactitud su estado de salud.

Se recomienda a las operadoras de turismo y turistas en general que deseen introducirse en el mundo del montañismo, aplicar el test psicofísico presentado en la presente propuesta metodológica y con base en sus resultados, empezar el proceso de aclimatación y/o capacitación; ya sea en alta montaña, media montaña o baja montaña.

\section{References:}

1. ANBCR, (. N. (2010). Curso de rescate vertical. Costa Rica.

2. ASEGUIM. (2015). Obtenido de https://aseguim.org/que-hacemos/

3. Aves y Conservación. (2011). Linea Base del Cantón Baños y Plan de Manejo del Corredor Ecológico Llanganates - Sangay.

4. BAENA, G. (2014). METODOLOGÍA DE LA INVESTIGACION . Mexico : Grupo Editorial Patria.

5. Contreras, E. (2011). Test de flexibilidad. Obtenido de https://gcvillanueva.webnode.cl/simce/test-de-flexibilidad/

6. Cooper, K. H. (1979). educacion fisica juvenil. Obtenido de http://edufisicayrecreacion.blogspot.com/p/test-fisicos.html

7. Devallenova, G. (2016). Repositorio de la Universidd d la Plata . Obtenido de http://blogs.unlp.edu.ar/planeamientofau/files/2013/05/FichaN\%C2\%BA-17-Gu\%C3\%ADa-metodol\%C3\%B3gica-para-laelaboraci\%C3\%B3n-de-una-EIA.pdf

8. Esteban Guillermo. (2011). Obtenido de https://gcvillanueva.webnode.cl/simce/test-de-flexibilidad/

9. Galeon, H. ((2013). ¿Qué es la espeleología. Obtenido de ¿Qué es la espeleología?: <http://espeleo.galeon.com/ 
10. Garcia, A. (05 de 10 de 2015). Psicomemorias. Obtenido de Psicomemorias: https://www.psicomemorias.com/no-estoy-loco-soyde-montana/

11. García, I. A. (Enero de 2011). La Bitácora del Dr. Ucha. Obtenido de http://ucha.blogia.com/2011/enero.php

12. Gomez, S. (2012 ). Metodologia de la Investigacion . Mexico : Red Tercer Milenio.

13. Gutierrez Cesar . (2013). edufisicayrecreacion. Obtenido de http://edufisicayrecreacion.blogspot.com/p/test-fisicos.html

14. Hernández, S. (1991). Metodología de la Investigación. Colombia.: Mac. Graw Hill.

15. Hgmexico. (2017). Equipo_alta_montana. Obtenido de http://www.hgmexico.com/equipo_alta_montana_iztaccihuatl.html

16. Homs, A. (2012). Tegnologia y montaña. Obtenido de Tegnologia y montaña: https://europadigital.com/2012/01/01/preparacion-fisicapara-la-montana/

17. Kuhn, T. (2001). Las estructuras de las revoluciones científicas. Mexico : Fondo de cultura.

18. Larrosa, D. (4 de Marzo de 2014). Test de aptitud física. Obtenido de http://www.abc.com.py/edicion-impresa/suplementos/escolar/test-deaptitud-fisica-1220796.html

19. Maya, E. (2014). Métodos y técnicas de la investigacion. Mexico.

20. Mc Ardle, W., \& Katch, F. \&. (2008). Fundamentos de fisiología del ejercicio. Mexico: McGraw Hill.

21. McColl, R. (2015). Enciclopedia de Geografía Mundial. Obtenido de http://www.geoenciclopedia.com/cordillera-de-los-alpes/

22. Mimenza, O. C. (s.f.). Tipos de test psicológicos: sus funciones y características.

23. Miró, J. (2006). Estrategia de la investigación descriptiva.

24. Moran, G. (2010). METODOS DE iNVESTIGACION . Mexico : Pearson .

25. NADAL, P. (2 de MAYO de 2016). EL VIAJERO. Obtenido de https://elviajero.elpais.com/elviajero/2016/04/29/actualidad/1461931 329_996570.html

26. Pellini, C. (22 de Octubre de 2014). Los Himalayas formación cadena montañosa origen ubicación templos. Historias y Biografías. Obtenido de htt:/historiaybiografías.com/himalayas/

27. Posada, L. (2013). Educacion fisica juvenil. Obtenido de Educacion Fisica Juvenil: http://edufisicayrecreacion.blogspot.com/p/testfisicos.html

28. Rojas, E. (13 de diciembre de 2016). ¿Qué es un guía UIAGM? Obtenido de ¿Qué es un guía UIAGM?: 
https://www.lacumbreonline.cl/blog/comunidad/que-es-un-guiauiagm/

29. SENAGUA. (2015).

30. Sole, J. (2002). Fundamentos del entrenamiento deportivo. Barcelona: Ergo.

31. Testsworld. (2019). Obtenido de https://es.testsworld.net/test-deresistencia-anaerobica.html

32. Turismo, M. d. (Abril de 2015). Proyecto Ecuador Potencia Turística. Obtenido de https://www.turismo.gob.ec/wpcontent/uploads/2015/04/Documento-Proyecto-Ecuador-PotenciaTur\%C3\%ADstica.pdf

33. Varo, R. (2006). Manual de técnica de la investigación educacional.

34. Vidales, H., \& Vidales, G. (2015). El equipo que debes llevar para subir al Iztaccihuarl. Obtenido de http://www.hgmexico.com/equipo_alta_montaña_iztaccihuatl.html 